Research Paper

\title{
A nomogram to predict HER2 status in breast cancer patients with HER2-borderline disease as determined via immunohistochemistry
}

\author{
Qianqian Guo ${ }^{1}$, Kai Chen ${ }^{2,3}$, Xiaojie Lin ${ }^{1}$, Yi Su${ }^{4}$, Rui Xu${ }^{1}$, Yan Dai ${ }^{1}$, Chang Qiu ${ }^{1}$, Xue \\ Song ${ }^{1}$, Siying Mao ${ }^{1}$ and Qianjun Chen ${ }^{1}$ \\ ${ }^{1}$ Department of Mammary Disease, Guangdong Provincial Hospital of Chinese Medicine, Guangzhou, Guangdong, P.R. China \\ ${ }^{2}$ Guangdong Provincial Key Laboratory of Malignant Tumor Epigenetics and Gene Regulation, Sun Yat-sen Memorial Hospital, \\ Sun Yat-sen University, Guangzhou, Guangdong, P.R. China \\ ${ }^{3}$ Breast Tumor Center, Sun Yat-sen Memorial Hospital, Sun Yat-sen University, Guangzhou, Guangdong, P.R. China \\ ${ }^{4}$ Department of Intensive Care, Foshan Hospital of Traditional Chinese Medicine, Guangzhou, Guangdong, P.R. China \\ Correspondence to: Qianjun Chen, email: cqj55@163.com \\ Kai Chen, email: chenkai23@mail.sysu.edu.cn
}

Keywords: breast cancer, HER2 status, IHC, calibration, nomogram

Received: October 27, $2016 \quad$ Accepted: March 11, $2017 \quad$ Published: July 17, 2017

Copyright: Guo et al. This is an open-access article distributed under the terms of the Creative Commons Attribution License 3.0 (CC BY 3.0), which permits unrestricted use, distribution, and reproduction in any medium, provided the original author and source are credited.

\section{ABSTRACT}

This study aimed to develop a nomogram to predict fluorescence in situ hybridization (FISH) assay results for HER2-borderline breast cancer as determined via immunohistochemistry (IHC) among patients in China. We reviewed a database of breast cancer patients diagnosed between January 2007 and April 2013 at our institutions. We used logistic regression to develop a nomogram and we used receiver operating characteristic curve analysis and calibration plots to validate our nomogram. In total, 1138, 301 and 344 patients had IHC-determined HER2-negative, HER2-borderline and HER2-positive disease, respectively. Within the training cohort, univariate and multivariate analyses suggested that estrogen receptor (ER) status, progesterone receptor (PR) status and tumor grade were significantly associated with HER2 status $(P<0.01)$. A nomogram was developed and the AUCs for the training and validation cohorts were 0.795 and 0.749 , respectively. The calibration plots suggested that the model was well calibrated. This new nomogram can be used to predict HER2 status in HER2-borderline breast cancer patients and will be particularly helpful to resource-limited countries.

\section{INTRODUCTION}

Globally, breast cancer is the most frequently diagnosed cancer and is the leading cause of cancer-related death among women. It is known that breast cancer is not a single disease; gene expression profiling via microarray analysis according to the mRNA expression levels of specific genes has provided a new method for classifying breast tumors into at least five distinct subtypes: luminal A, luminal B, normal breast-like, HER2-positive and basal-like [1,2]. Amplification of the HER2/neu gene, resulting in over-expression of this receptor, is found in $20-25 \%$ of human breast cancers $[3,4]$. Determination of
HER2 over-expression in breast carcinomas has become important in clinical practice, with the advent of antiHER2 therapy as demonstrated in clinical trials [5-7], such as the BCIRG 006, NSABP B31/N9831 and HEAR trials. All these trials have shown that trastuzumab can be beneficial to HER2-positive breast cancer patients. Therefore, the HER2 status is crucial for the guidance of treatment decisions involving the use of trastuzumab, and measurement of the HER2 status is becoming a standard recommendation in the pretreatment work-up of patients with invasive breast cancer.

Before starting anti-HER2 therapy, physicians must be sure of the accuracy of the test results that show HER2 
Table 1: Clinical pathological characteristics (training cohort and validation cohort)

\begin{tabular}{|c|c|c|c|}
\hline Characteristic & Training cohort $(n=1482)$ & Validation cohort $(n=139)$ & $P$ \\
\hline Age & & & 0.508 \\
\hline Median(range) & $49(25-87)$ & $51(31-84)$ & \\
\hline <50yr_no.(\%) & $466(31)$ & $65(47)$ & \\
\hline$>=50 y$ r_no. $(\%)$ & $1016(69)$ & $74(53)$ & \\
\hline ER & & & 0.05 \\
\hline negative_no.(\%) & $415(28)$ & $22(16)$ & \\
\hline positive_no.(\%) & $1067(72)$ & $117(84)$ & \\
\hline PR & & & 0.07 \\
\hline negative_no.(\%) & $449(30)$ & $37(27)$ & \\
\hline positive_no.(\%) & $1033(70)$ & $102(73)$ & \\
\hline Ki67 & & & 0.01 \\
\hline$<14 \%$ _no.(\%) & $548(37)$ & $62(45)$ & \\
\hline$>=14 \%$ no. $(\%)$ & $934(63)$ & $77(55)$ & \\
\hline T-STAGE & & & 0.44 \\
\hline T1_no.(\%) & $683(46)$ & $66(47)$ & \\
\hline T2-4_no.(\%) & $799(54)$ & $72(53)$ & \\
\hline N-STAGE & & & 0.13 \\
\hline N0_no.(\%) & $882(60)$ & $79(57)$ & \\
\hline N1_no.(\%) & $393(27)$ & $45(32)$ & \\
\hline N2_no.(\%) & $124(8)$ & $5(4)$ & \\
\hline N3_no.(\%) & $83(6)$ & $10(7)$ & \\
\hline Grade & & & 0.22 \\
\hline 1_no.(\%) & $70(5)$ & $6(4)$ & \\
\hline 2_no.(\%) & $1058(71)$ & $88(63)$ & \\
\hline 3 no. $(\%)$ & $354(24)$ & $44(32)$ & \\
\hline
\end{tabular}

over-expression [8-11]. The expression of the HER2 protein is determined via immunohistochemistry (IHC) in routine practice due to the ease of performance and low cost of IHC [12]. IHC is widely used to detect the expression of HER2 protein and is the preferred method for genetic screening and testing [13-16]. In some tumors, it is difficult to differentiate between $1+$ and $2+$ or between $2+$ and $3+$ HER2 expression scores. Hoang [17] previously reported low interobserver reproducibility for distinguishing cases with 2+ HER2 expression from cases with $3+$ HER2 expression. Thus, in current clinical practice, the FISH assay is still considered to be the gold standard technique for evaluation of the HER2 status [18-23].

The American Society of Clinical Oncology/ College of American Pathologists (ASCO/CAP)[24] also recommend that if results are equivocal, reflex testing should be performed using an alternative assay (IHC or ISH). Because in many laboratories around the world, FISH is the first line test and IHC is the reflex test. However, in addition to the wellknown socioeconomic disparities within China [25], substantial regional disparities exist, generally leading to insufficient financial resources and health-care staff in undeveloped regions. IHC is still the first step in HER2 detection. The cost of medical services in China (including surgery and nursing) is very low compared to that in other countries; for example, surgery fees for a mastectomy in Shanghai are \$360. Although the FISH assay only costs approximately $\$ 300$, this cost is an economic burden for poor people. Therefore, we hypothesized that a predictive model could be developed to predict the results of the FISH assay for patients with 
Table 2: Univariate and multivariate analysis of risk factors for HER2 character in training cohort

\begin{tabular}{lcccc}
\hline \multirow{2}{*}{ Features } & $\begin{array}{c}\text { Univariate } \\
\text { analysis P value }\end{array}$ & HR & Multivariate analysis & P value \\
\cline { 2 - 5 } age & NS & - & 95\%CI & NS \\
ER & $<0.01$ & 0.98 & $0.98-0.99$ & $<0.01$ \\
PR & $<0.01$ & 0.98 & $0.98-0.99$ & $<0.01$ \\
Ki67 & NS & - & - & NS \\
Grade & $<0.01$ & 2.93 & $2.22-3.88$ & $<0.01$ \\
T-STAGE & NS & - & - & NS \\
N-STAGE & $<0.01$ & - & - & NS \\
\hline
\end{tabular}

HER2-borderline disease as determined via IHC. For patients of low socioeconomic status who cannot afford the FISH assay and/or trastuzumab therapy, our model will be helpful in predicting the results of the FISH assay and in providing clarifying information to determine the appropriate treatment options such as chemotherapy and/ or endocrine therapy.

In China [26], the incidence of breast cancer among women has increased every year from 2000 to 2011, and this disease has become the leading cause of cancer-related death among women younger than 45 years old. In fact, health professionals in China have long been a group with low income levels [27], and China's per capita income is lower than that of the United States. Therefore, it is necessary to produce a predictive model for the results of the FISH assay in HER2-borderline breast cancer patients.

\section{RESULTS}

\section{Clinicopathological characteristics of the study population}

A total of 1783 female breast cancer patients were included, and the study cohort had a median age of 50 years (range 25-101 years). This study included 1138 $(63.82 \%), 301(16.89 \%)$ and $344(19.29 \%)$ patients determined to be HER2-negative, HER2-borderline and HER2-positive, respectively. Thus, 301 patients had a HER2 score of $2+$, of which one case was still not confirmed based on the result of a FISH assay; 161 of these patients did not undergo a FISH assay. Among the patients with IHC-determined HER2-borderline disease, 96 and 43 had negative and positive results for HER2 status on the FISH assay, respectively. Patients with HER2-negative or HER2-positive disease as determined via IHC represented the training cohort, whereas those with IHC-determined HER2-borderline $(2+)$ disease represented the validation cohort. Table 1 compares the baseline characteristics of the training cohort and the validation cohort.

\section{Development of a nomogram}

All variables analysis including age, ER, PR, Ki67, $\mathrm{T}$-stage, $\mathrm{N}$-stage, grade were included in the analysis. The univariate analyses selected ER, PR, N-stage and grade, while in the multivariate analyses revealed ER status, PR status and tumor grade as independent predictors of HER2 status (Table 2). The performance of the nomogram in the validation population was analyzed in terms of discrimination and calibration. A nomogram was developed using multivariate logistic regression analysis including the above predictors (Figure 1). As an internal validation, we performed ROC curve analysis, and the area under the curve (AUC) was 0.795 in the training cohort (Figure 2a). We used ROC curve analysis of the nomogram in our validation cohort for external validation. The AUC for the validation cohort was 0.749 (Figure 3a). The discrimination of the nomogram is satisfactory in both populations with AUC values $>0.70$. The calibration plots (Figure $2 b$ ) revealed that the nomogram was internally well calibrated, with an average estimated error of $2.28 \%$, and the calibration plots revealed that the predicted probability according to the nomogram was slightly higher than the actual probability, with an average estimated error of $10.8 \%$ (Figure $3 \mathrm{~b}$ ). The main concern is the $\mathrm{P}$ value of Unreliability index, which the two groups were all 1 . It is shown that the null hypothesis is not rejected (H0: intercept $=0$, slope $=1$ ), that is, the fitted line coincides with the 45 degree line, which means the prediction is accurate. We used YOUDEN index to determine the cut off value, which with a sensitivity of $81 \%$, specificity of $64 \%$, positive predictive value of $50 \%$, negative predictive value of $88 \%$. Although this result is very good, but may not necessarily acceptable in clinical.

\section{DISCUSSION}

For breast cancer patients who do not undergo the FISH assay, the ability to predict the FISH assay result would be informative for clinical decision making. In 
this study, we developed a nomogram using a training cohort of patients with IHC-determined HER2-negative or HER2-positive disease. The results of ROC curve analysis suggested that the nomogram has valid discrimination ability, although the calibration plots revealed that the actual predicted deviation and actual probability were slightly greater in the validation cohort than in the training cohort. Our nomogram calculated the predicted probability of a positive FISH assay result. In the absence of further studies, the cut-off value for this nomogram in clinical practice remains unclear. From our perspective, $5 \%$ of the positive HER2 status results can be considered as HER2negative, although these patients still need to be evaluated by a clinician. In reality, clinicians will not act on a $2+$ HER2 score in most cases, even if the likelihood of HER2positive disease is high based on our nomogram. Further, the cost of trastuzumab or other anti-HER2 therapies far outweighs the cost of a single FISH assay. Our nomogram may benefit the detection of a negative HER2 status. In fact, the results of our nomogram should be fully discussed with patients during clinical decision making.

Previous data have shown the relationships between HER2 status and other IHC-determined indexes. An inverse association has been described between HER2 over-expression and the presence of the steroid hormone receptors ER and $\mathrm{PR}$ in both clinical correlative studies [28-33] and experimental models [34, 35]. Konecny
[36] found that patients with higher levels of HER2 amplification had significantly lower levels of ER/PR than patients with lower levels of HER2 amplification. This finding was consistent with the results of other studies [37, 38]. Our study confirmed that the ER and PR statuses were positively correlated with the HER2 status. Coincidentally, tumor grade was also previously shown to be associated with the HER2 status as determined via IHC alone [12, 39]. HER2 expression was previously found to correlate with a higher nuclear grade but not with the tumor stage [40]; a majority of studies have reported an association between high tumor grade and HER2/neu status [41]. However, none of these studies developed a predictive model incorporating these predictors. Our study is the first to develop a nomogram to perform this prediction.

Clinical studies have confirmed that HER2-positive breast cancer patients have significantly higher risks of recurrence and mortality than HER2-negative breast cancer patients. In Slamon's study [3], breast cancer patients harboring greater than five copies of HER2 had shorter disease-free survival durations $(\mathrm{P}=0.015)$ and overall survival durations $(\mathrm{P}=0.06)$ than those without HER2 gene amplification. Several other studies have also shown an association between patient prognosis and the molecular subtype of breast cancer. Millar [42] found a 5 -year locoregional recurrence rate of $15 \%$ for HER2enriched tumors, compared to a $1 \%$ rate for luminal $\mathrm{A}$

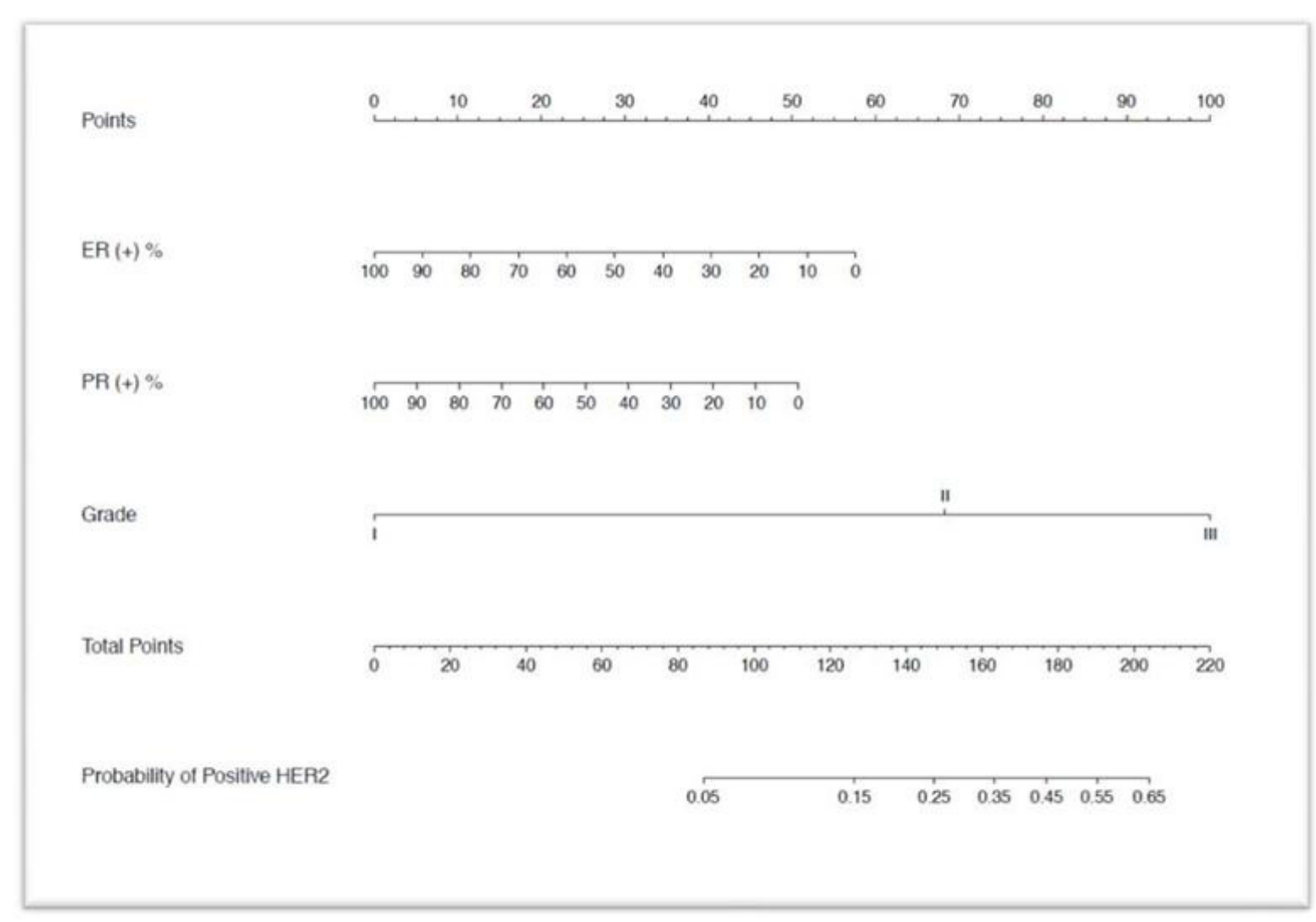

Figure 1: Nomogram to calculate the probability of HER2 positive in breast carcinoma. 


\section{ROC Curve}

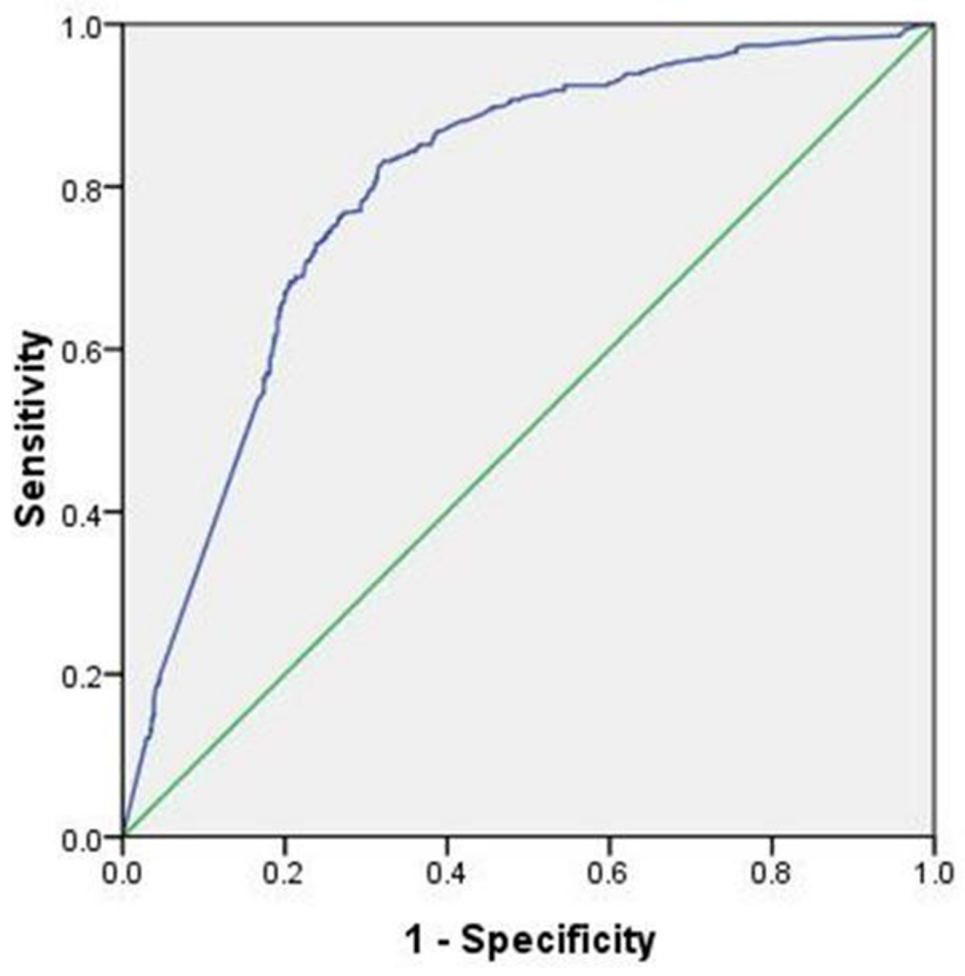

Diagonal segments are produced by ties.

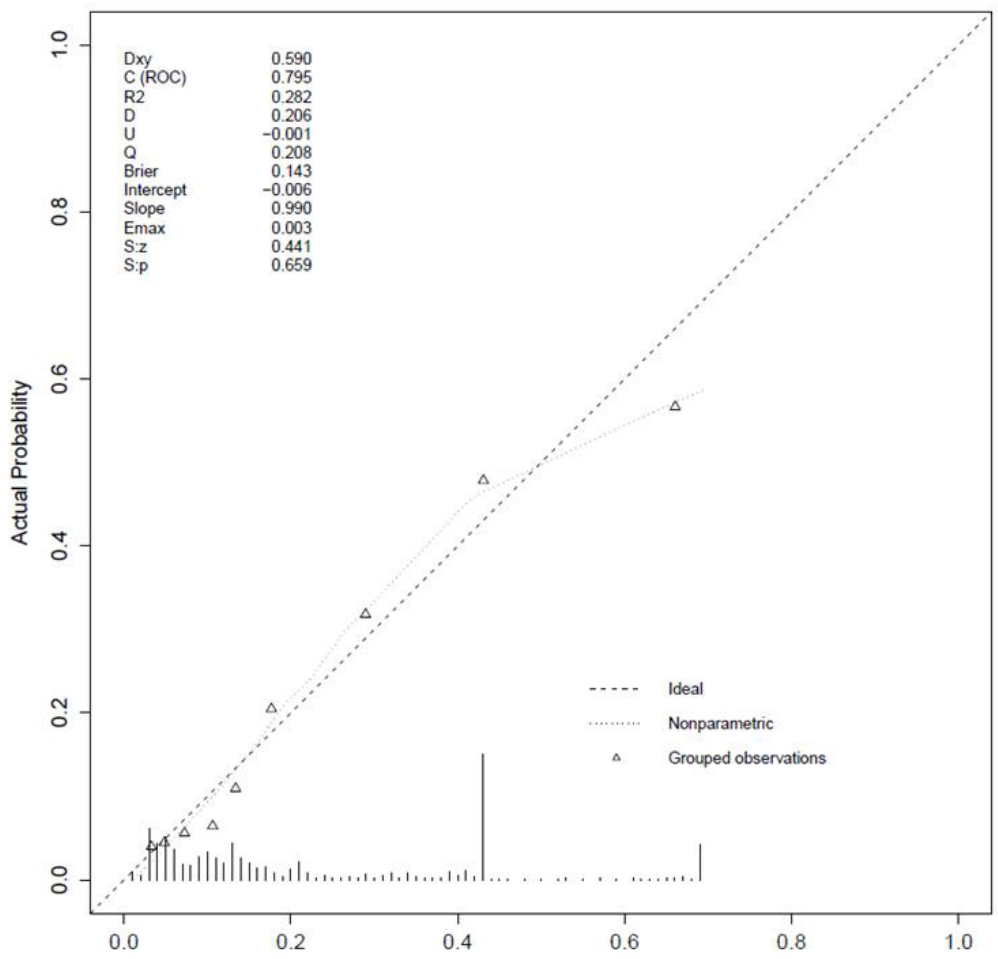

Figure 2: (a) ROC curve of the training set. (b) Calibration plots of the nomogram validated internally in the training cohort. 


\section{ROC Curve}

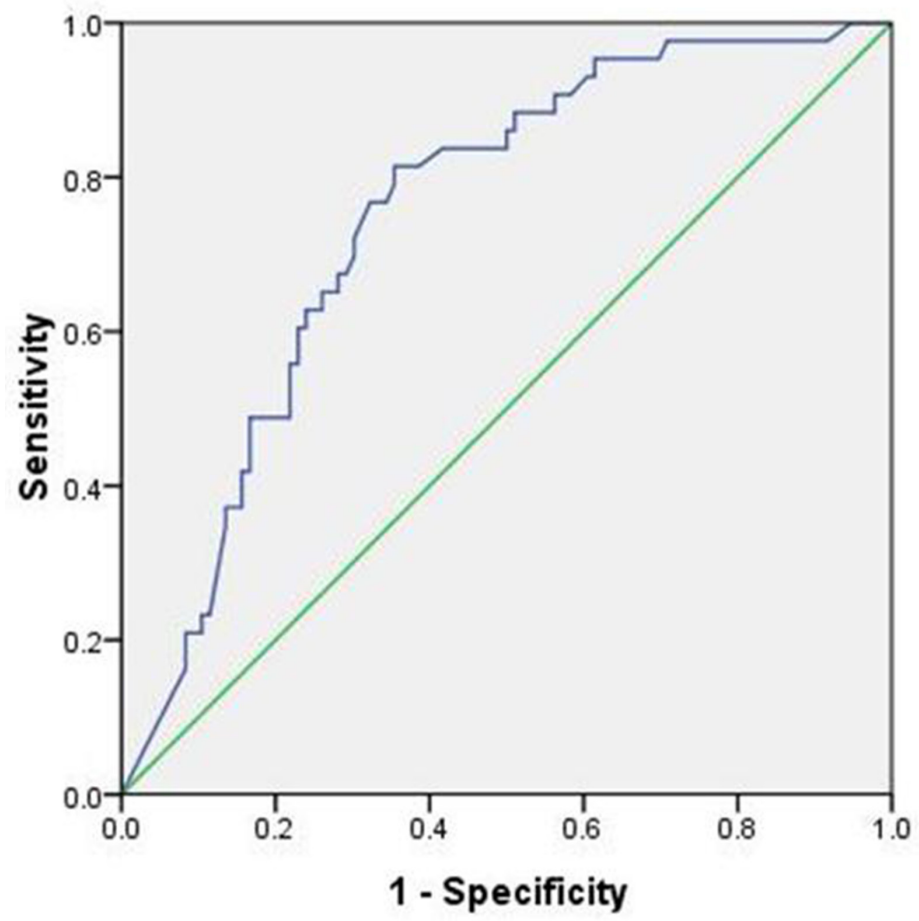

Diagonal segments are produced by ties.

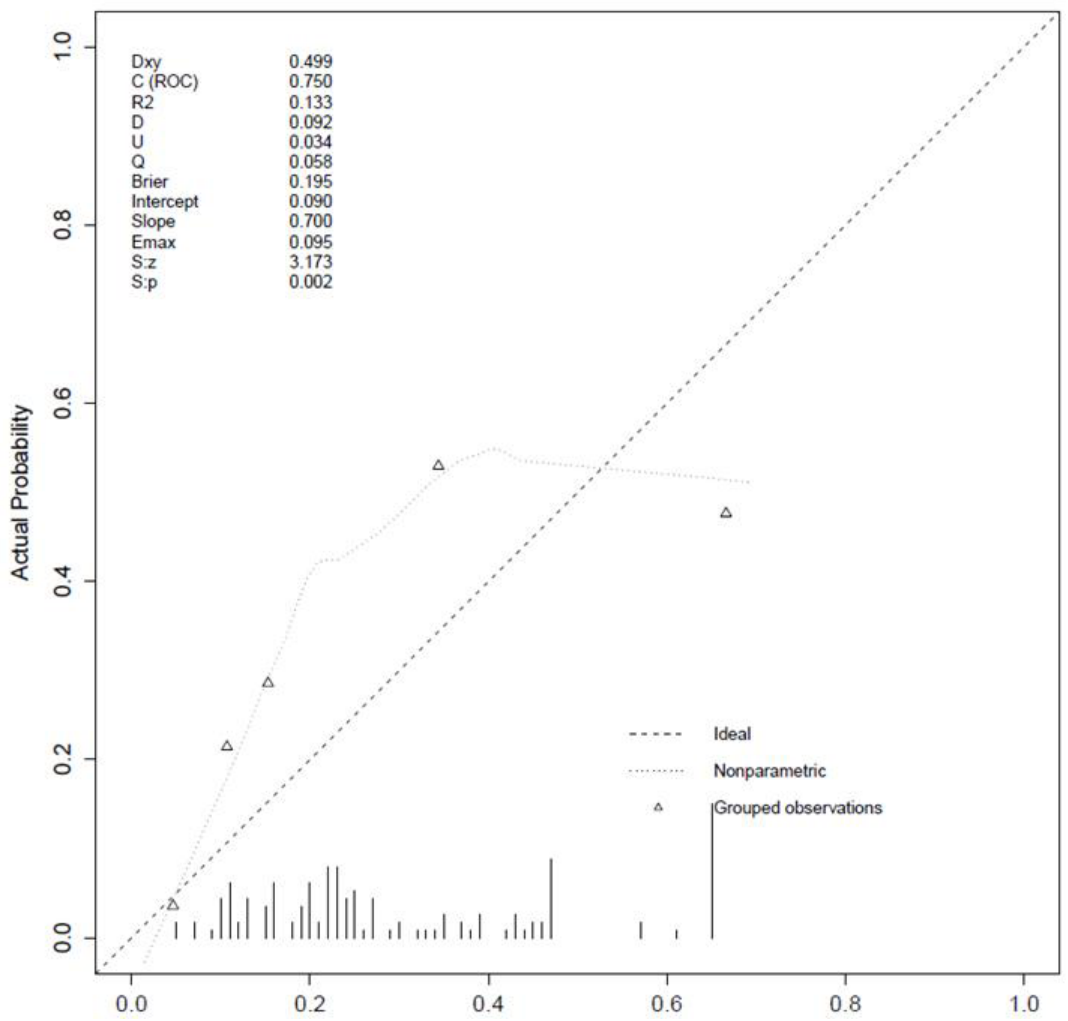

Figure 3: (a) ROC curve of the validation set. (b) Calibration plots of the nomogram validated internally in the validation cohort. 
tumors. Voduc et al.[43] reported that the HER2-enriched and basal subtypes of breast cancer were associated with an increased risk of local and regional recurrence. Therefore, it is extremely important to know the HER2 status during clinical decision making. However, China has many rural areas and many poor patients who do not have sufficient resources and medical insurance coverage. Even in cities such as Beijing, 8.9\% of patients have no access to HER2 testing, and among those who have uncertain IHC results regarding their HER2 status, 10\% of patients do not receive a FISH assay [44]. Therefore, we predict that the situation is much worse in rural areas, although no data are currently available. Additionally, trastuzumab is typically not included in national or local reimbursement listings, resulting in prohibitively high out-of-pocket expenses for this drug for many patients [45]. Thus, our prediction model has practical value for patients of low socioeconomic status. For patients who cannot afford the FISH assay and trastuzumab therapy, our model will be helpful for predicting their HER2 status. If an patient with IHC-determined HER2-borderline disease were predicted to be HER2-positive and that patient could not afford trastuzumab, a stronger chemotherapy regimen, e.g., dose-dense $\mathrm{AC}-\mathrm{T}$, could be considered as an alternative to $\mathrm{TC}$ regimens.

Several limitations of this study should be noted. 1) The small sample size of our study population may have compromised the power of our statistical analyses. For example, the PR showed a lot of original data because of the small sample size problem, which we did not use the residual analysis method to evaluate the abnormal value, so the value still retained which increases the degree of discrete regression relationship to some extent. 2) This is not a multicenter validation study, which may limit the results of the study. 3) Inconsistent detection of Ki-67 may affect its relationship with HER2. 4) Patients receiving neoadjuvant chemotherapy were not included in our study. Therefore, our nomogram is not valid for these patients. 5) All patients in our study cohort had invasive ductal carcinoma. Therefore, it is unclear whether our nomogram can be applied to other pathological types of breast cancer, such as mucinous carcinoma and medullary carcinoma. 6) Internal validation is not sufficient, We still need external data for further verification. 7) In our study, data were not available for several important indexes, e.g., LVI, Allred score for ER status, EIC, P53, and TOPO II status. Our nomogram appears to be oversimplified in that it only takes into account ER status, PR status, and histological grade. Therefore, in this model, every poorly differentiated triple-negative tumor may have the same probability of HER2 positivity as a poorly differentiated carcinoma that is hormone receptor-negative and (actually) HER2positive. Thus, more studies are needed to determine whether adding the indexes noted above would improve our predictive model.

\section{MATERIALS AND METHODS}

\section{Patients and tissue specimens}

We reviewed an electronic database of breast cancer patients diagnosed between January 2007 and April 2013 at our institutions. The ethics committee of Guangdong Provincial Hospital of Chinese Medicine exempted this retrospective study from full ethics review. Our study included 1783 patients treated for operable breast cancer who were diagnosed at Guangdong Provincial Hospital of Chinese Medicine. The main inclusion criterion was newly confirmed early invasive ductal breast cancer with a pathological stage of I-III without any prior treatment (chemotherapy, hormone therapy or radiotherapy). The exclusion criteria were multifocal or bilateral breast cancer. We collected the relevant information about the patients, including age, ER status, PR status, Ki-67 index, HER2 status, T-stage, N-stage and tumor grade. All of our primary data (de-identified) on the patients included in this study are available upon request.

All patients underwent surgical treatment, and the study samples consisted of postoperative paraffinized specimens. Specimens with a volume fraction of $10 \%$ neutral formalin were fixed for 6-48 h; then, the specimens were embedded in paraffin and sectioned into 2-4- $\mu \mathrm{m}$ sections. HE staining confirmed the presence of invasive ductal carcinoma, and the IHC method was used to determine the HER2 status, ER status, PR status, Ki-67 index and tumor grade. If the result of IHC for HER2 was a score of $2+$, the FISH assay was performed. Expression levels of standard biomarkers at the time of diagnosis were reviewed in all sections that were subjected to IHC. The ER and PR levels were regarded as positive if at least $1 \%$ of tumor nuclei stained positive for the respective marker [46].

The US FDA and ASCO/CAP recommend that HER2 IHC scores of 0 and 1+ be regarded as HER2negative and that HER2 scores of $3+$ be considered as HER2-positive. A case of invasive breast cancer with an HER2 score of $2+$ is regarded as HER2-borderline and should be further assessed via a FISH assay, which is considered the gold standard test of HER2 status. The number of HER2 gene amplifications was determined via FISH using an FDA-approved dual-color PathVysion HER2 DNA Probe Kit and a Paraffin Pretreatment Kit. The kit contains a mixture of a spectrum of orange-labeled HER2/neu gene probes and a spectrum of green-labeled centromere controls for chromosome 17. The HER2/ CEN-17 ratio was calculated by dividing the total HER2 signal by the total CEN-17 signal. A negative HER2 FISH assay result [18] is defined as a HER2/CEP17 ratio of less than 1.8 or an average of fewer than four copies of the HER2 gene per nucleus. A positive FISH assay result is defined as an elevated HER2 gene copy number (average 
of $>$ six gene copies/nucleus) or a HER2/CEP17 ratio of greater than 2.2.

\section{Statistics}

Descriptive statistics were obtained for the entire dataset, and all statistical analyses were performed using SPSS version 19.0 software. The Chi-square test was used to compare categorical variables, and the KolmogorovSmirnov $Z$ test was used to compare continuous variables. Univariate and multivariate logistic regression analyses were used to determine the independent factors predicting HER2 over-expression. The "Enter" method was used to select variables for the logistic regression analyses. We used the rms package in $\mathrm{R}$ software to develop a nomogram based on the results of the logistic regressions. For model validation, we used receiver operating characteristic (ROC) curve analysis and a calibration plot to evaluate the performance of the nomogram. The calibration plot was a graphical representation of the agreement between the observed outcome frequencies and the predicted probabilities, which was used to verify whether or not the model has fitted the data well. All statistical tests were two-sided, and a value of $\mathrm{P}<0.05$ was considered significant.

\section{CONCLUSION}

Our nomogram predicts the results of the FISH assay in breast cancer patients with IHC-determined HER2-borderline disease. In the future, we suggest three directions for further investigation. First, more external validation studies are needed to validate our nomogram. Second, the cost-effectiveness of our model must be evaluated. Third, a randomized controlled trial may be needed to confirm that more intensive adjuvant therapy would provide a survival benefit to patients predicted to have a high risk for positive HER2 status based on the nomogram.

\section{ACKNOWLEDGMENTS}

The authors would like to thank all working group members for their contribution to this study and to express their heartfelt gratitude to their mentor and research team.

\section{CONFLICTS OF INTEREST}

The authors declare no conflicts of interest.

\section{REFERENCES}

1. Perou CM, Sørlie T, Eisen MB, van de Rijn M, Jeffrey SS, Rees CA, Pollack JR, Ross DT, Johnsen H, Akslen LA, Fluge O, Pergamenschikov A, Williams C, et al. Molecular portraits of human breast tumours. Nature. 2000;406:747752. doi: $10.1038 / 35021093$.

2. Sorlie T, Tibshirani R, Parker J, Hastie T, Marron JS, Nobel A, Deng S, Johnsen H, Pesich R, Geisler S, Demeter J, Perou CM, Lønning PE, et al. Repeated observation of breast tumor subtypes in independent gene expression data sets. Proc Natl Acad Sci U S A. 2003;100:8418-8423. https://doi.org/10.1073/pnas.0932692100.

3. Slamon DJ, Clark GM, Wong SG, Levin WJ, Ullrich A, McGuire WL. Human breast cancer: correlation of relapse and survival with amplification of the HER-2/ neu oncogene. Science. 1987;235:177-182. https://doi. org/10.1126/science. 3798106 .

4. Slamon DJ, Godolphin W, Jones LA, Holt JA, Wong SG, Keith DE, Levin WJ, Stuart SG, Udove J, Ullrich A. Studies of the HER-2/neu proto-oncogene in human breast and ovarian cancer. Science. 1989;244:707-712. https://doi. org/10.1126/science.2470152.

5. Perez EA, Romond EH, Suman VJ, Jeong JH, Sledge G, Geyer CE Jr, Martino S, Rastogi P, Gralow J, Swain SM, Winer EP, Colon-Otero G, Davidson NE, et al. Trastuzumab plus adjuvant chemotherapy for human epidermal growth factor receptor 2-positive breast cancer: planned joint analysis of overall survival from NSABP B-31 and NCCTG N9831. J Clin Oncol. 2014;32:3744-3752. https://doi. org/10.1200/JCO.2014.55.5730.

6. Gianni L, Dafni U, Gelber RD, Azambuja E, Muehlbauer S, Goldhirsch A, Untch M, Smith I, Baselga J, Jackisch C, Cameron D, Mano M, Pedrini JL, et al. Treatment with trastuzumab for 1 year after adjuvant chemotherapy in patients with HER2-positive early breast cancer: a 4-year follow-up of a randomised controlled trial. Lancet Oncol. 2011;12:236-244. https://doi.org/10.1016/ S1470-2045(11)70033-X.

7. Slamon D, Eiermann W, Robert N, Pienkowski T, Martin M, Press M, Mackey J, Glaspy J, Chan A, Pawlicki M, Pinter T, Valero V, Liu MC, et al. Adjuvant trastuzumab in HER2positive breast cancer. N Engl J Med. 2011;365:1273-1283. https://doi.org/10.1056/NEJMoa0910383.

8. Latta EK, Tjan S, Parkes RK, O'Malley FP. The role of HER2/neu overexpression/amplification in the progression of ductal carcinoma in situ to invasive carcinoma of the breast. Mod Pathol. 2002;15:1318-1325. https://doi. org/10.1097/01.MP.0000038462.62634.B1.

9. Liu JJ, Shen R, Chen L, Ye Y, He G, Hua K, Jarjoura D, Nakano T, Ramesh GK, Shapiro CL, Barsky SH, Gao JX. Piwil2 is expressed in various stages of breast cancers and has the potential to be used as a novel biomarker. Int J Clin Exp Pathol. 2010;3:328-337.

10. McCormick SR, Lillemoe TJ, Beneke J, Schrauth J, Reinartz J. HER2 assessment by immunohistochemical analysis and fluorescence in situ hybridization: comparison of HercepTest and PathVysion commercial assays. Am J Clin Pathol. 2002;117:935-943. https://doi. org/10.1309/3643-F955-7Q6B-EWWL. 
11. Ellis CM, Dyson MJ, Stephenson TJ, Maltby EL. HER2 amplification status in breast cancer: a comparison between immunohistochemical staining and fluorescence in situ hybridisation using manual and automated quantitative image analysis scoring techniques. J Clin Pathol. 2005;58:710-714. https://doi.org/10.1136/jcp.2004.023424.

12. Van de Vijver MJ. Assessment of the need and appropriate method for testing for the human epidermal growth factor receptor-2 (HER2). Eur J Cancer. 2001;37:S11-S17. https:// doi.org/10.1016/S0959-8049(00)00403-2.

13. Pauletti G, Dandekar S, Rong H, Ramos L, Peng H, Seshadri R, Slamon DJ. Assessment of methods for tissuebased detection of the HER-2/neu alteration in human breast cancer: a direct comparison of fluorescence in situ hybridization and immunohistochemistry. J Clin Oncol. 2000;18:3651-3664.

14. Eichhorn PJ, Baselga J. HER2 signatures in breast cancer: ready to go to print? J Clin Oncol. 2010;28:1809-1810. https://doi.org/10.1200/JCO.2009.26.7146.

15. Dowsett M, Bartlett J, Ellis IO, Salter J, Hills M, Mallon E, Watters AD, Cooke T, Paish C, Wencyk PM, Pinder SE. Correlation between immunohistochemistry (HercepTest) and fluorescence in situ hybridization (FISH) for HER-2 in 426 breast carcinomas from 37 centres. J Pathol. 2003;199:418-423. https://doi.org/10.1002/path.1313.

16. Perez EA, Roche PC, Jenkins RB, Reynolds CA, Halling $\mathrm{KC}$, Ingle JN, Wold LE. HER2 testing in patients with breast cancer: poor correlation between weak positivity by immunohistochemistry and gene amplification by fluorescence in situ hybridization. Mayo Clin Proc. 2002;77:148-154. https://doi.org/10.4065/77.2.148.

17. Hoang MP, Sahin AA, Ordòñez NG, Sneige N. HER-2/ neu gene amplification compared with HER-2/neu protein overexpression and interobserver reproducibility in invasive breast carcinoma. Am J Clin Pathol. 2000;113:852-859. https://doi.org/10.1309/VACP-VLQA-G9DX-VUDF.

18. Walker RA, Bartlett JM, Dowsett M, Ellis IO, Hanby AM, Jasani B, Miller K, Pinder SE. Her2 testing in the UK: further update to recommendations. J Clin Pathol. 2008;61:818-824. https://doi.org/10.1136/jcp.2007.054866.

19. Bartlett JM, Going JJ, Mallon EA, Watters AD, Reeves JR, Stanton P, Richmond J, Donald B, Ferrier R, Cooke TG. Evaluating HER2 amplification and overexpression in breast cancer. J Pathol. 2001;195:422-428. https://doi. org/10.1002/path.971.

20. Meijer SL, Wesseling J, Smit VT, Nederlof PM, Hooijer GK, Ruijter H, Arends JW, Kliffen M, van Gorp JM, Sterk L, van de Vijver MJ. HER2 gene amplification in patients with breast cancer with equivocal IHC results. J Clin Pathol. 2011;64:1069-1072. https://doi.org/10.1136/ jclinpath-2011-200019.

21. Shah SS, Ketterling RP, Goetz MP, Ingle JN, Reynolds CA, Perez EA, Chen B. Impact of American society of clinical oncology/College of American Pathologists guideline recommendations on HER2 interpretation in breast cancer.
Hum Pathol. 2010;41:103-106. https://doi.org/10.1016/j. humpath.2009.07.001.

22. Starczynski J, Atkey N, Connelly Y, O'Grady T, Campbell FM, di Palma S, Wencyk P, Jasani B, Gandy M, Bartlett JM; UKNEQAS. HER2 gene amplification in breast cancer: a rogues' gallery of challenging diagnostic cases: UKNEQAS interpretation guidelines and research recommendations. Am J Clin Pathol. 2012;137:595-605. https://doi. org/10.1309/AJCPATBZ2JFN1QQC.

23. Hammond ME. ASCO-CAP guidelines for breast predictive factor testing: an update. Appl Immunohistochem Mol Morphol. 2011;19:499-500. https://doi.org/10.1097/ PAI.0b013e31822a8eac.

24. Wolff AC, Hammond ME, Hicks DG, Dowsett M, McShane LM, Allison KH, Allred DC, Bartlett JM, Bilous M, Fitzgibbons P, Hanna W, Jenkins RB, Mangu $\mathrm{PB}$, et al. Recommendations for human epidermal growth factor receptor 2 testing in breast cancer: American Society of Clinical Oncology/College of American Pathologists clinical practice guideline update. J Clin Oncol. 2013;31:3997-4014. https://doi.org/10.1200/ JCO.2013.50.9984.

25. Lee B, Peng J, Li G, He J. Regional economic disparity, financial disparity, and national economic growth: evidence from China. Rev Dev Econ. 2012;16:342-358. https://doi. org/10.1111/j.1467-9361.2012.00666.x.

26. Chen W, Zheng R, Baade PD, Zhang S, Zeng H, Bray F, Jemal A, Yu XQ, He J. Cancer statistics in China, 2015. CA Cancer J Clin. 2016;66:115-132.

27. Tian Y, Hua LJ, Chao WM. Chinese doctors' salaries. Lancet. 2008;371:1576-1577. https://doi.org/10.1016/ S0140-6736(08)60684-4.

28. Zeillinger R, Kury F, Czerwenka K, Kubista E, Sliutz G, Knogler W, Huber J, Zielinski C, Reiner G, Jakesz R, Staffen A, Reiner A, Wrba F, et al. HER-2 amplification, steroid receptors and epidermal growth factor receptor in primary breast cancer. Oncogene. 1989;4:109-114.

29. Borg A, Tandon AK, Sigurdsson H, Clark GM, Fernö M, Fuqua SA, Killander D, McGuire WL. HER-2/neu amplification predicts poor survival in node-positive breast cancer. Cancer Res. 1990;50:4332-4337.

30. Marsigliante S, Muscella A, Ciardo V, Barker S, Leo G, Baker V, Mottaghi A, Vinson GP, Storelli C. Enzyme-linked immunosorbent assay of HER-2/neu gene product $(\mathrm{p} 185)$ in breast cancer: its correlation with sex steroid receptors, cathepsin D and histologic grades. Cancer Lett. 1993;75:195-206. https://doi. org/10.1016/0304-3835(93)90062-E.

31. Quénel N, Wafflart J, Bonichon F, de Mascarel I, Trojani M, Durand M, Avril A, Coindre JM. The prognostic value of c-erbB2 in primary breast carcinomas: a study on 942 cases. Breast Cancer Res Treat. 1995;35:283-291. https:// doi.org/10.1007/BF00665980.

32. Andrulis IL, Bull SB, Blackstein ME, Sutherland D, Mak C, Sidlofsky S, Pritzker KP, Hartwick RW, Hanna W, Lickley 
L, Wilkinson R, Qizilbash A, Ambus U, et al. neu/erbB-2 amplification identifies a poor-prognosis group of women with node-negative breast cancer. Toronto Breast Cancer Study Group. J Clin. Oncol. 1998;16:1340-1349.

33. Tagliabue E, Menard S, Robertson JF, Harris L. c-erbB-2 expression in primary breast cancer. Int $\mathrm{J}$ Biol Markers. 1999; 14:16-26.

34. Benz CC, Scott GK, Sarup JC, Johnson RM, Tripathy D, Coronado E, Shepard HM, Osborne CK. Estrogendependent, tamoxifen-resistant tumorigenic growth of MCF-7 cells transfected with HER2/neu. Breast Cancer Res Treat. 1992;24:85-95. https://doi.org/10.1007/BF01961241.

35. Pietras RJ, Arboleda J, Reese DM, Wongvipat N, Pegram MD, Ramos L, Gorman CM, Parker MG, Sliwkowski MX, Slamon DJ. HER-2 tyrosine kinase pathway targets estrogen receptor and promotes hormone-independent growth in human breast cancer cells. Oncogene. 1995;10:2435-2446.

36. Konecny G, Pauletti G, Pegram M, Untch M, Dandekar S, Aguilar Z, Wilson C, Rong HM, Bauerfeind I, Felber M, Wang HJ, Beryt M, Seshadri R, et al. Quantitative association between HER-2/neu and steroid hormone receptors in hormone receptor-positive primary breast cancer. J Natl Cancer Inst. 2003;95:142-153. https://doi. org/10.1093/jnci/95.2.142.

37. Huang HJ, Neven P, Drijkoningen M, Paridaens R, Wildiers H, Van Limbergen E, Berteloot P, Amant F, Vergote I, Christiaens MR. Association between tumour characteristics and HER-2/neu by immunohistochemistry in 1362 women with primary operable breast cancer. J Clin Pathol. 2005;58:611-616. https://doi.org/10.1136/jcp.2004.022772.

38. Almasri NM, Al Hamad M. Immunohistochemical evaluation of human epidermal growth factor receptor 2 and estrogen and progesterone receptors in breast carcinoma in Jordan. Breast Cancer Res. 2005;7:R598-R604. https://doi. org/10.1186/bcr1200.

39. Taucher S, Rudas M, Mader RM, Gnant M, Dubsky P, Bachleitner T, Roka S, Fitzal F, Kandioler D, Sporn E, Friedl J, Mittlböck M, Jakesz R. Do we need HER-2/neu testing for all patients with primary breast carcinoma?
Cancer. 2003;98:2547-2553. https://doi.org/10.1002/ cncr. 11828.

40. Berger MS, Locher GW, Saurer S, Gullick WJ, Waterfield MD, Groner B, Hynes NE. Correlation of c-erbB-2 gene amplification and protein expression in human breast carcinoma with nodal status and nuclear grading. Cancer Res. 1988;48:1238-1243.

41. Kaptain S, Tan LK, Chen B. Her-2/neu and breast cancer. Diagn Mol Pathol. 2001;10:139-152. https://doi. org/10.1097/00019606-200109000-00001.

42. Millar EK, Graham PH, O'Toole SA, McNeil CM, Browne L, Morey AL, Eggleton S, Beretov J, Theocharous C, Capp A, Nasser E, Kearsley JH, Delaney G, et al. Prediction of local recurrence, distant metastases, and death after breastconserving therapy in early-stage invasive breast cancer using a five-biomarker panel. J Clin Oncol. 2009;27:47014708. https://doi.org/10.1200/JCO.2008.21.7075.

43. Voduc KD, Cheang MC, Tyldesley S, Gelmon K, Nielsen TO, Kennecke H. Breast cancer subtypes and the risk of local and regional relapse. J Clin Oncol. 2010;28:16841691. https://doi.org/10.1200/JCO.2009.24.9284.

44. Yuan XM, Wang N, Ouyang T, Yang L, Song MY, Lin BY, Xie YT, Li JF, Pan KF, You WC, Zhang L. Current status of diagnosis and treatment of primary breast cancer in Beijing, 2008. Chin J Cancer Res. 2011;23:38-42. https:// doi.org/10.1007/s11670-011-0038-y.

45. National Health and Family Planning Commission of China. National essential drugs list. http://www.moh.gov. cn/mohywzc/s3580/201303/f01 fcc9623284509953620abc 2ab189e/files/961cfc3a86584f8888e9140b1c208438.pdf. Accessed July 2, 2013. [in Chinese.]

46. Hammond ME, Hayes DF, Dowsett M, Allred DC, Hagerty KL, Badve S, Fitzgibbons PL, Francis G, Goldstein NS, Hayes M, Hicks DG, Lester S, Love R, et al. American Society of Clinical Oncology/College of American Pathologists guideline recommendations for immunohistochemical testing of estrogen and progesterone receptors in breast cancer. J Clin Oncol. 2010;28:27842795. https://doi.org/10.1200/JCO.2009.25.6529. 